\title{
MORTALIDADE NO PRIMEIRO ANO DE VIDA E A DISTRIBUIÇÃO DE RENDA E DE RECURSOS PÜBLICOS DE SAÚDE, SĀO PAULO (BRASIL)
}

\author{
Carlos Augusto Monteiro * \\ Maria Helena D'Aquino Benício * \\ Márcia F. A. Baldijão**
}

\begin{tabular}{l|l|}
${ } }$ \\
\hline
\end{tabular}

MONTEIRo, C. A. et al. A mortalidade no primeiro ano de vida e a distribuiça de renda e de recursos públicos de saúde. Säo Paulo (Brasil) Rev. Saúde públ., S. Paulo, 14:515-39, 1980.

REsUMO: Foi feito estudo para identificar em torno de 1976 a distribuicico da freqü̈ência do óbito infantil, a distribuiç̃o da renda $e$ a distribuição da disponibilidade de determinados recursos públicos de saúde nos 55 distritos e sub-distritos do municipio de São Paulo (Brasil), para analisar as possiveis identificaçóes entre estas distribuiçôes. A freqüencia do óbito infantil foi crescente no sentido centro-periferia da cidade, o mesmo ocorrendo com a concentracão de familias de baixa renda. Os recursos públicos de saúde estudados, água do abastecimento público, leitos hospitalares e centros de saude do Estado, foram decrescentes no mesmo sentido centro-periferia. Tanto a distribuicão crescente da baixa renda quanto a distribuição decrescente dos recursos públicos acham-se positiva e significativamente correlacionadas à distribuiçấo crescente da mortalidade infantil. Na área periférica da cidade, correspondente à área de maior mortalidade, encontra-se a mais alta concentração de familias de baixa renda $e$, também, as menores disponibilidades de recursos públicos de saúde providos direta ou indiretamente pelo Estado. Conclui-se que renda e recursos públicos operam no mesmo sentido, ou seja, de reforço mútuo às desigualdades registradas ao nivel da mortalidade infantil, e não no sentido inverso, como talvez se pudesse crer. Discute-se o duplo processo desigual da distribuição das riquezas na cidade de São Paulo, o que se dá na distribuição direta da renda c o que se dá, posteriormente, quando o Estado participa daquela distribuição provendo serviços públicos.

Unitermos: Mortalidade infantil, S. Paulo, Brasil. Renda. Recursos de saúde.

\section{INTRODUSAU}

Reconhece-se no risco de morte no primeiro ano de vida não só medida indicadora das condições de saúde da população menor de un ano, mas também medida sintetizadora de condições de saúde e qualidade de vida da população em geral. Este reco-

* Do Departamento de Nutrição da Faculdade de Saúde Pública da Universidade de São Pauln - Av. Dr. Arnaldo, 715 - 01255 - Săo Paulo, SP - Brasil.

* Da Fundação Sistema Estadual de Análise de Dados - Av. Casper Líbero. 464 - 01033 São Paulo, SP - Brasil. 
MONTEIRO, C. A. et al. A mortalidade no primeiro ano de vida e a distribuição de renda e de recursos públicos de saúde, São Paulo (Brasil). Rev. Saúde públ., S. Paulo, 14:515-39, 1980.

nhecimento se apóia na ampla influência que os principais determinantes da qualidade de vida podem, em potencial, exercer sobre as causas comuns de óbito no primeiro ano. Cumpre destacar que o nível de acesso a estes determinantes - alimentação, moradia, educação, cuidado à saúde - tem historicamente determinado $\cap$ nível absoluto da mortalidade infantil das sociedades, bem como os diferentes niveis de mortalidade a que chegam os seus estratos sociais com diferentes acessos aqueles determinantes ${ }^{1}$.

$\mathrm{Na}$ cidade de São Paulo, no periodo 1968-70, a Investigação Interamericana de Mortalidade na Infância revelou nivel excepcionalmente alto do coeficiente de mortalidade infantil, mais elevado do que em outras cidades latino-americanas de igual ou menor desenvolvimento. Laurenti ", examinando as causas daquela mortalidade, atribui este fato principalmente à elevada mortalidade por doenças infecciosas e causas perinatais. Estas, por sua vez, sendo decorrentes da total inadequação do saneamento básico da cidade, extensivel inclusive aos seus hospitais-maternidade, e da insuficiente atenção médico-sanitária à população materno-infantil, evidenciada pela baixa cobertura de pré-natal e de vacinações. Segundo Laurenti ${ }^{\circ}$, papel contributório sumamente relevante seria desempenhado pela desnutrição, cuja prevalência no periodo imediato à investigação citada mostrou-se elevada $e$ diretamente ligada ao montante de renda das familias 8 .

Enı um estudo subre a distribuição geugráfica de nascimentos e óbitos infantis no Município de São Paulo em 1971, Baldijão ${ }^{3}$, evidencia uma distribuição heterogênea tanto do coeficiente de mortalidade infantil quanto da mortalidade infantil proporcional. A periferia da cidade apresentava naquela época coeficiente de mortalidade infantil e mortalidade infantil proporcional, respectivamente, duas e três vezes superiores aos encontrados na área central. Evidencia também, a importância das variáveis saneamento básico, nivel de renda e caracteristi- cas demográficas na explicação da heterogênea distribuição da mortalidade, concluindo pela importância decisiva do saneamento e da renda e pela inter-relação existente entre todas as variáveis.

Do exposto, verifica-se que serian determinantes do nivel de renda das familias e os determinantes do saneamento básico e da atenção materno-infantil aqueles que, em grande parte, determinariam os niveis da mortalidade infantil no municipio. Considerando que enı São Paulo o saneamento e a assistência de saúde materno-infantil săo providos direta ou indiretamente pelo Estado, poder-se-ia resumidamente dizer que a mortalidade infantil no município de São Paulo estaria a depender, de um lado, do montante de rendimentos auferidos pelas familias e, de outro, da disponibilidade de determinados recursos públicos de saúde como água, esgoto, hospitais e centros de saúde.

O propósito deste trabalho é verificar como está distribuida geograficamente no municipio a frequiência do óbito infantil e verificar como estão distribuídos renda $e$ recursos públicos de saúde. Seu propósito analítico é o de estudar, tendo como referência a distribuição da mortalidade infantil, o sentido assumido pelas distribuições da renda e dos recursos públicos.

Isento da preocupação de quantificar a açăo de variáveis sobre a mortalidade infantil, o trabalho pretenderá explorar a concordância ou discordância de dois momentos comprovadamente importantes na determinação da freqüência do óbito infantil, o que se dá na pura e simples distribuição direta das riquezas geradas e o que se dá quando o Estado intermedia aquela distribuição provendo serviços públicos.

\section{METODOLOGIA}

Para o estudo da distribuição geográfica da mortalidade infantil foi utilizado o Movimento do Registro Civil do Estado de São Paulo de $1976^{11}$ que traz para 0 ano e segundo local de residência, o número 
MONTEIRo, C. A. et al. A mortalidade no primeiro ano de vida e a distribuição de renda e de recursos públicos de saúde, São Paulo (Brasil). Rev. Saúde públ., S. Paulo, 14:515-39, 1980.

de nascimentos e óbitos. Dados sobre o nível de renda da população segundo local de residência foram obtidos através do levantamento amostral procedido pela Secretaria de Negócios Metropolitanos do Estado de São Paulo, em 1977 13. A informação sobre saneamento básico refere-se ao consumo de água do abastecimento público registrado pela Companhia de Saneamento Básico do Estado de São Paulo (SABESP) 4 em cada um dos 55 sub-distritos e distritos do município no $4^{\circ}$ bimestre de 1976. Para os mesmos sub-distritos foram obtidos o número de leitos-maternidade e o número de profissionais médicos trabalhando em centros de saúde do Estado. $O$ número de leitos foi obtido através de levantamento da Coordenadoria de Assistência Hospitalar da Secretaria da Saúde do Estado realizado em 197512 e o número de médicos através do Censo de Pessoal daquela Secretaria no ano de $1974^{10}$.

A coleta dos dados de renda e do número de leitos e médicos em anos diferentes, porém próximos, do ano do estudo da mortalidade não deve prejudicar o propósito analítico do estudo na medida em que se pretende apenas explorar tendências de distribuição e não quantificar relações causais. Além disso, ao contrário do abastecimento de água, estudado no mesmo ano, não há evidências de que a distribuição da renda e dos leitos e médicos tenha se alterado de forma importante na cidade no espaço de um ou dois anos.

Como indicadores das variáveis pesquisadas foram adotados:

1. Coeficiente de mortalidade infantil: número de óbitos de menores de um ano para cada mil nascidos vivos.

2. Mortalidade infantil proporcional: percentagem de óbitos de menores de um ano no total dos óbitos.

3. Proporção de famílias de baixa renda: percentagem de familias com rendimentos até 3,6 salários mínimos.
4. Consumo de água per capita: metros cúbicos de água consumidos por cada habitante.

5. Disponibilidade de leitos-maternidade: número de leitos-maternidade para cada 1.000 habitantes.

6. Disponibilidade de médicos de centros de saúde do Estado: número de profissionais médicos alocados em centros de saúde do Estado para cada 10.000 habitantes.

Os 55 sub-distritos e distritos que compõem o município de São Paulo (Fig. 1) foram ordenados segundo cada um dos indicadores de 2 a 6 e, a seguir, agrupados para que fossem obtidos mapas de identificação da distribuição das variáveis mortalidade, renda e recursos públicos de saúde.

O agrupamento dos sub-distritos no caso da mortalidade infantil proporcional foi executado de modo a determinar três conjuntos de tamanhos populacionais semelhantes. Isto foi efetivado pelo agrupamento na ordem crescente da mortalidade dos primeiros 27 sub-distritos, dos seguintes 14 e dos ültimos 14 .

Os agrupamentos dos sub-distritos no caso da proporção das famílias de baixa renda e da disponibilidade de recursos públicos foram realizados procurando-se obter das ordens crescente da baixa renda e decrescente das disponibilidades, conjuntos compostos também de 27,14 e 14 sub-distritos.

A concordância ou discordância assumida pelas distribuições das variáveis renda $e$ recursos públicos em função da distribuição da mortalidade infantil foi examinada inicialmente pela justaposição dos mapas referentes àquelas duas variáveis com 0 mapa baseado na distribuição da mortalidade infantil proporcional. Em seguida, foi apreciada à luz da análise estatística da correlação existente entre a ordenação dos sub-distritos e distritos conforme renda e recursos públicos com a ordenação existente conforme a mortalidade infantil proporcio- 


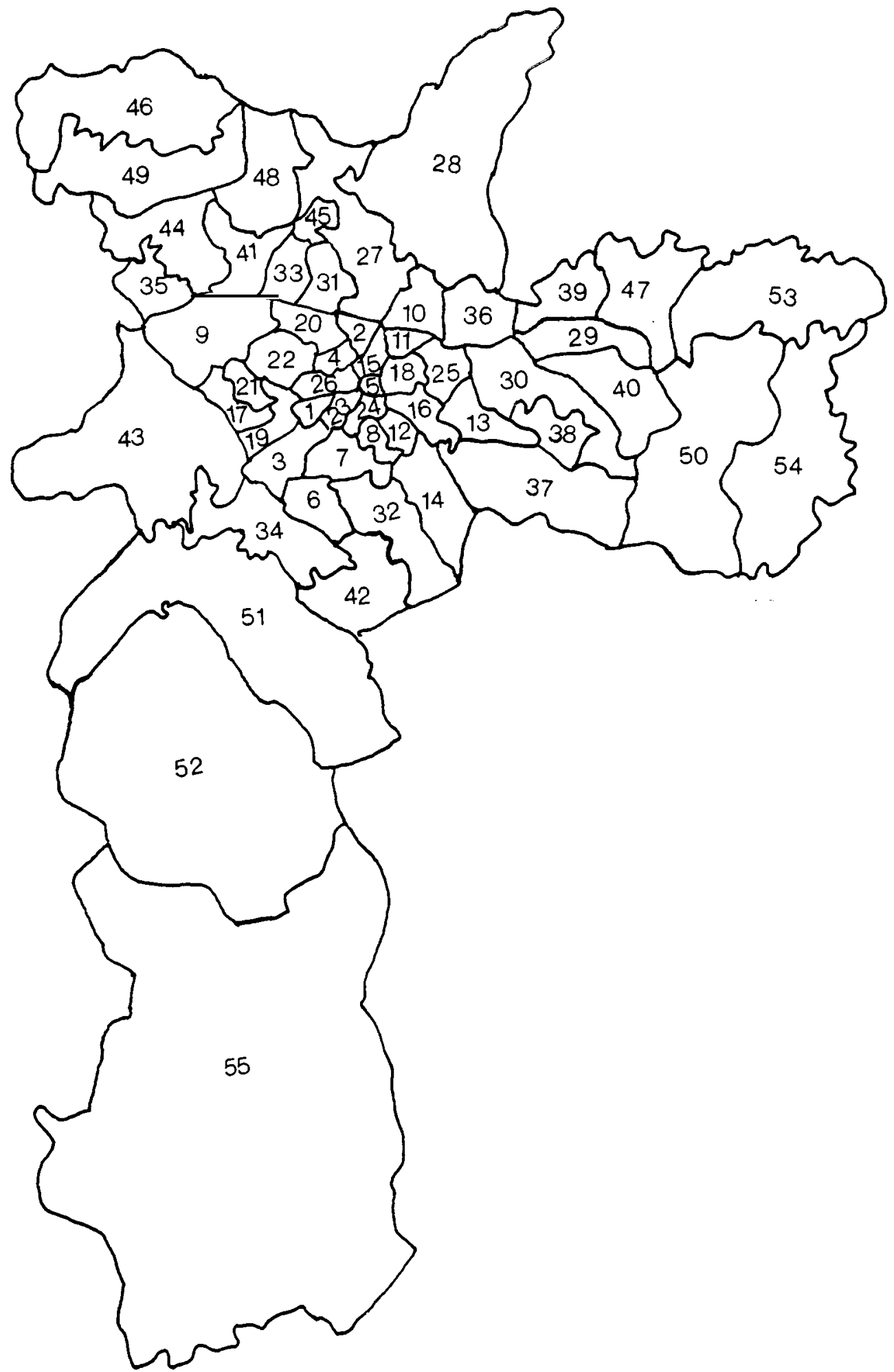

Fig. 1 - Sub-distritos e distritos do município de Sāo Paulo. 1. C.César. 2. B.Retiro. 3. J.Paulista, 4. Sta.Cecília, 5. Sé, 6. Indianópolis, 7. V.Mariana, 8. Aclimação, 9. Lapa, 10. V.Guilherme, 11. Pari, 12. Cambuci, 13. Alto Mooca, 14. Ipiranga, 15. Sta.Efigênia, 16. Moóca, 17. Pinheiros, 18. Brás, 19. J.América, 20. B.Funda, 21. V.Madalena, 22. Perdizes, 23. B.Vista, 24. Liberdade, 25. Belenzinho, 26. Consolação, 27. Santana, 28. Tucuruvi. 29. Penha, 30. Tatuapé, 31. C.Verde, 32. Saúde. 33. Limão, 34. Ibirapuera. 35. V.Jaguara. 36. V.Maria, 37. V.Prudente, 38. V.Formosa, 39.Cangaiba, 40. V.Matilde, 41. N.Sra. do o, 42. Jabaquara, 43. Butantā, 44. Pirituba, 45. V.N.Cachoeirinha, 46. Perus, 47. E.Matarazzo, 48. Brazilândla, 49. Jaraguá, 50. Itaquera, 51. Sto.Amaro, 52. C.do Socorro, 53. S.M.Paullsta, 54. Gualanazes, 55. Parelheiros. 
MONTEIRo, C. A. et al. A mortalidade no primeiro ano de vida e a distribuição de renda e de recursos públicos de saúde, São Paulo (Brasil). Rev. Saúde públ., S. Paulo, 14:515-39, 1980.

nal. A correlação foi medida através do coeficiente de correlação de postos de Spearman.

Como última etapa, para os três tercis populacionais representados nos três conjuntos de sub-distritos extraídos a partir da ordem crescente da mortalidade infantil proporcional, foram calculados os valores médios dos indicadores de renda e de recursos públicos.

\section{RESULTADOS}

\subsection{Distribuiçăo da mortalidade infantil}

No ano de 1976, o movimento do registro civil do municipio acusou 193.524 nascidos vivos que, nascidos em 1976, foram registrados neste mesmo ano. Adicionalmente, ainda nascidos em 1976, porém registrados em 1977, encontram-se outros 13.165, o que produz um total de 206.689 nascidos vivos para o ano de 1976. Neste mesmo ano foram registrados 15.508 óbitos de crianças menores de um ano igualmente residentes no município, o que produz para este um coeficiente de mortalidade infantil de $\mathbf{7 5 , 0 3}$ óbitos para cada mil nascidos vivos.

O registro dos eventos vitais segundo local de residência, executado a partir de 1971, abre a possibilidade imediata da desagregação do conjunto dos óbitos e nascimentos do município para cada uma das $\mathbf{5 5}$ unidades de distritos e sub-distritos que 0 compõem. A mortalidade infantil assim calculada ainda denota, entretanto, falhas em diferenciar local de residência de local de ocorrência do evento vital, levando a que alguns sub-distritos passem a possuir valores aberrantes de mortalidade infantil, prejudiciais a uma correta divisão do município segundo áreas de diferentes mortalidades. Para esta última finalidade prestase melhor não o coeficiente de mortalidade infantil, mas a proporção de óbitos de menores de um ano no conjunto dos óbitos registrados ${ }^{3}$. Esta proporção além de estar intimamente relacionada à verdadeira mortalidade infantil de cada distrito ou sub-distrito, deve sofrer poucas distorções pois, independentemente dos registros de nascimento, não é atingida pelo fenômeno de invasão e/ou evasão de óbitos se o mesmo for uniforme em todas as idades.

A Tabela 1 traz ordenada de forma crescente a proporção dos óbitos de menores de um ano nos 55 distritos e sub-distritos do municipio. Em um extremo da Tabela encontra-se o central sub-distrito de Cerqueira César, pertencente à área de afluência da cidade conhecida como a "área dos jardins", com 10,53\% dos seus óbitos procedendo de crianças menores de um ano. No extremo oposto está o distrito de Parelheiros, situado na periferia sul da cidade, com 46,54\% dos óbitos sendo de crianças menores de um ano.

Três conjuntos de distritos e sub-distritos, de tamanhos populacionais semelhantes $e$ de distintas intensidades da proporção de óbitos infantis, são formados com o agrupamento dos primeiros 27 sub-distritos com proporções de $10,53 \%$ a $20,09 \%$ com 0 agrupamento dos seguintes 14 sub-distritos com proporções de $20,44 \%$ a $30,16 \%$ e com o agrupamento dos últimos 14 subdistritos e distritos com proporçōes de $30,39 \%$ a $46,54 \%$.

A Fig. 2 situa a posição dos três conjuntos formados a partir da intensidade da proporção de óbitos infantis, verificando-se que os mesmos se configuram como áreas aproximadamente concêntricas onde a área de baixa mortalidade infantil proporcional seria a área mais central e a área de alta mortalidade infantil proporcional a área mais periférica, ambas separadas por uma área de intermediária mortalidade infantil proporcional. O cálculo do coeficiente de mortalidade infantil para estas três áreas, possivelmente menos comprometido pelas falhas de registro, uma vez que parte da evasão e invasão dos registros faz-se internamente às áreas, acusa 52,44 óbitos infantis para cada mil nascidos vivos na área central, 62,99 na área intermediária e 97,06 na área periférica, confirmando-se o fato de que se está trabalhando não apenas com 


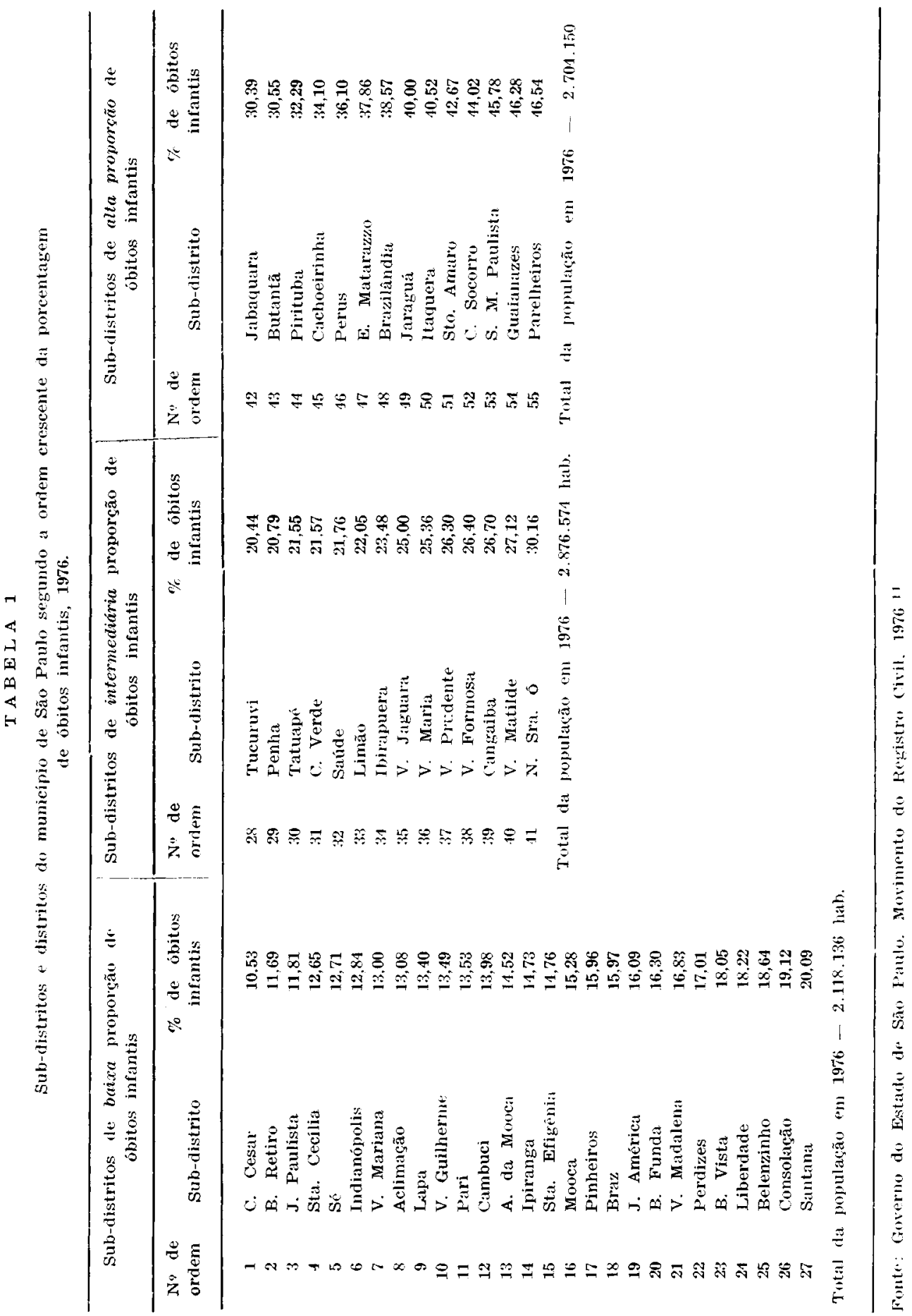




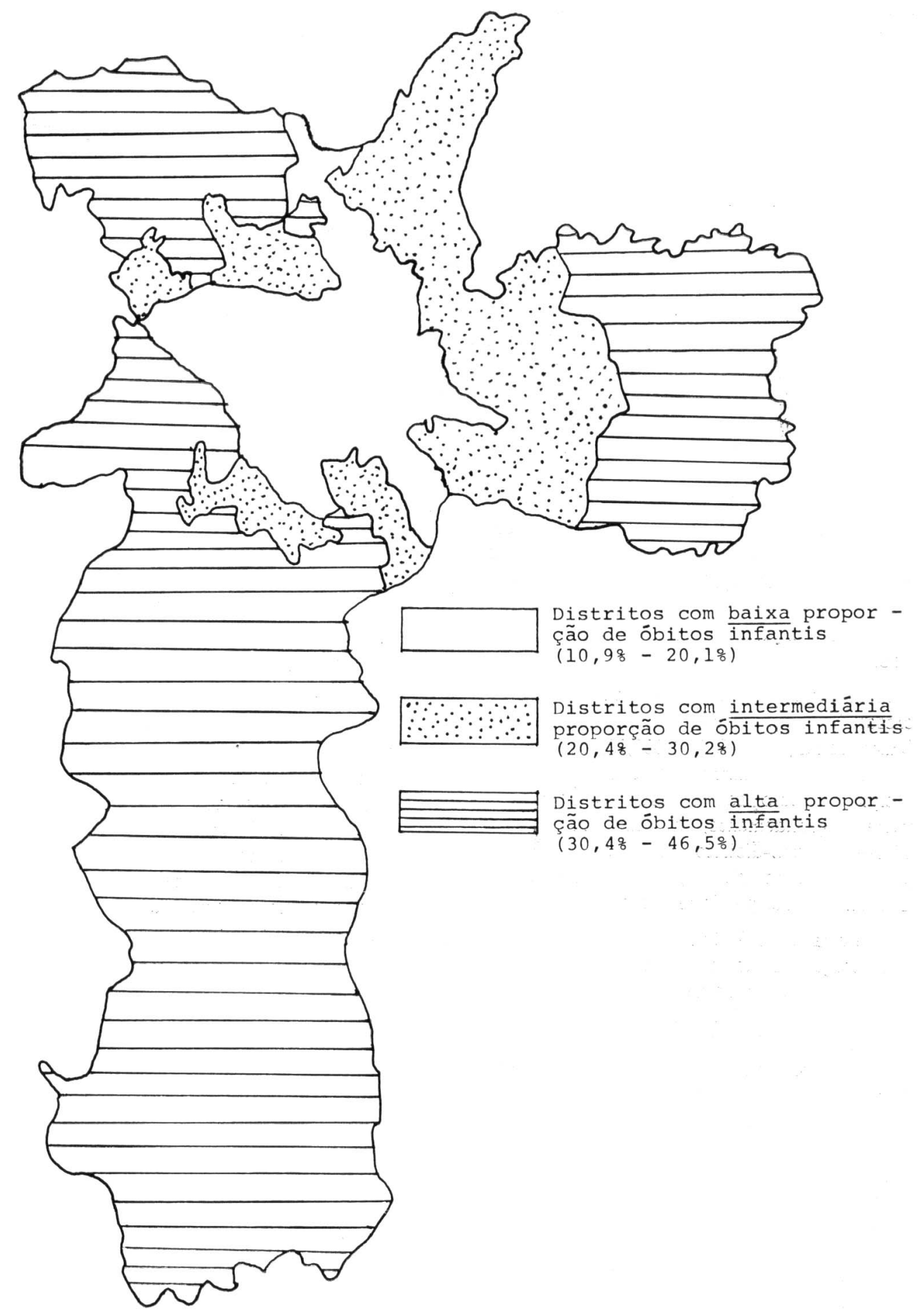

Fig. 2 - Delimitação das áreas de baixa, intermediaria e alta proporção de óbitos infantis (São Pauld, 1976). 
MONTEIRo, C. A. et al. A mortalidade no primeiro ano de vida e a distribuição de renda e de recursos públicos de saúde, São Paulo (Brasil). Rev. Saúde públ., S. Paulo, 14:515-39, 1980.

áreas de diferentes proporções de óbitos infantis, mas, verdadeiramente, com áreas de diferentes riscos de mortalidade infantil.

\subsection{Distribuição da renda}

Segundo levantamento amostral da Secretaria de Negócios Metropolitanos do Estado de São Paulo realizado no município em $1977,34,9 \%$ das familias pesquisadas tinham rendimentos mensais de até $\mathrm{Cr} \$ 4.000,00 *$, à época correspondente a 3,6 salários mínimos e insuficientes para a aquisição das necessidades básicas de uma família com alimentação, moradia, vestuário e transporte. o mesmo levantamento evidenciou um extremo processo de concentração da renda, ilustrado pelo fato de que o montante dos rendimentos das $2,3 \%$ famílias mais ricas do municipio superava largamente os rendimentos conjuntos daquelas $34,9 \%$ mais pobres.

A Tabela 2 traz ordenada de forma crescente a percentagem de familias de baixa renda, até $\operatorname{Cr} \$ 4.000,00$, para cada um dos 55 sub-distritos e distritos do municipio. Como se vê, estas percentagens variam grandemente, de um mínimo de $10,2 \%$ no sub-distrito de Cerqueira César a um máximo de $61,2 \%$ no distrito de Guaianazes na periferia leste da cidade.

Analogamente à divisão do municipio en três conjuntos de sub-distritos e distritos de diferentes intensidades de mortalidade, procede-se a divisão do mesmo em três conjuntos de diferentes frequiências de familias de baixa renda. Os primeiros 27 subdistritos de menores proporçōes de famílias com baixa renda constituem o conjunto de baixa proporção de baixa renda familiar, de $10,2 \%$ a $32,3 \%$. Os seguintes 14 sub-distritos de frequièncias intermediárias de famílias com baixa renda constituem o conjunto de intermediária proporção de baixa renda familiar, de $32,9 \%$ a $40,8 \%$. Os últimos 14 sub-distritos de maiores proporçōes de familias com baixa renda constituem o conjunto de alta proporção de baixa renda familiar, de $41,7 \%$ a $61,2 \%$.

A Fig. 3 situa a posição dos três conjuntos formados à base da frequiência da baixa renda familiar. Pode-se notar novamente a configuração de três agrupamentos concêntricos, onde desta vez o agrupamento mais central corresponde ao conjunto de sub-distritos de baixa proporção de baixa renda familiar e o mais periférico ao de alta proporção de baixa renda familiar.

\subsection{Distribuição dos recursos públicos de saúde}

Como recursos publicos de saúde, neste trabalho serāo discutidos o abastecimento de água, a disponibilidade de leitos hospitalares para maternidade e a disponibilidade de centros de saúde, esta medida através do quadro de médicos. A escolha destes recursos esteve baseada no elo que os liga ao perfil de mortalidade da cidade, conforme já discutido anteriormente, e tambén na factibilidade do seu estudo segundo sub-distritos e distritos. Ainda que direta ou indiretamente providos pelo Estado, e portanto de caráter público, os recursos estudados apresentam distintos modos de ligação com o Estado. Estas ligaçōes serão explicitadas no decorrer dos resultados e deverão ser levadas em conta na análise dos mesmos.

\subsubsection{Distribuição do abastecimento público de água}

A rede de abastecimento público de água do município de São Paulo é operada pela SABESP. A expansão e manutenção desta rede ainda que custeada em parte pelos usuários, é decisivamente subsidiada pelos cofres públicos.

Neste estudo ao invés de se utilizar proporção de domicílios abastecidos, recorre-se ao consumo per capita de água. Este indi-

\footnotetext{
* Equivalente a US\$ 288.00 ao câmbio de 1977.
} 


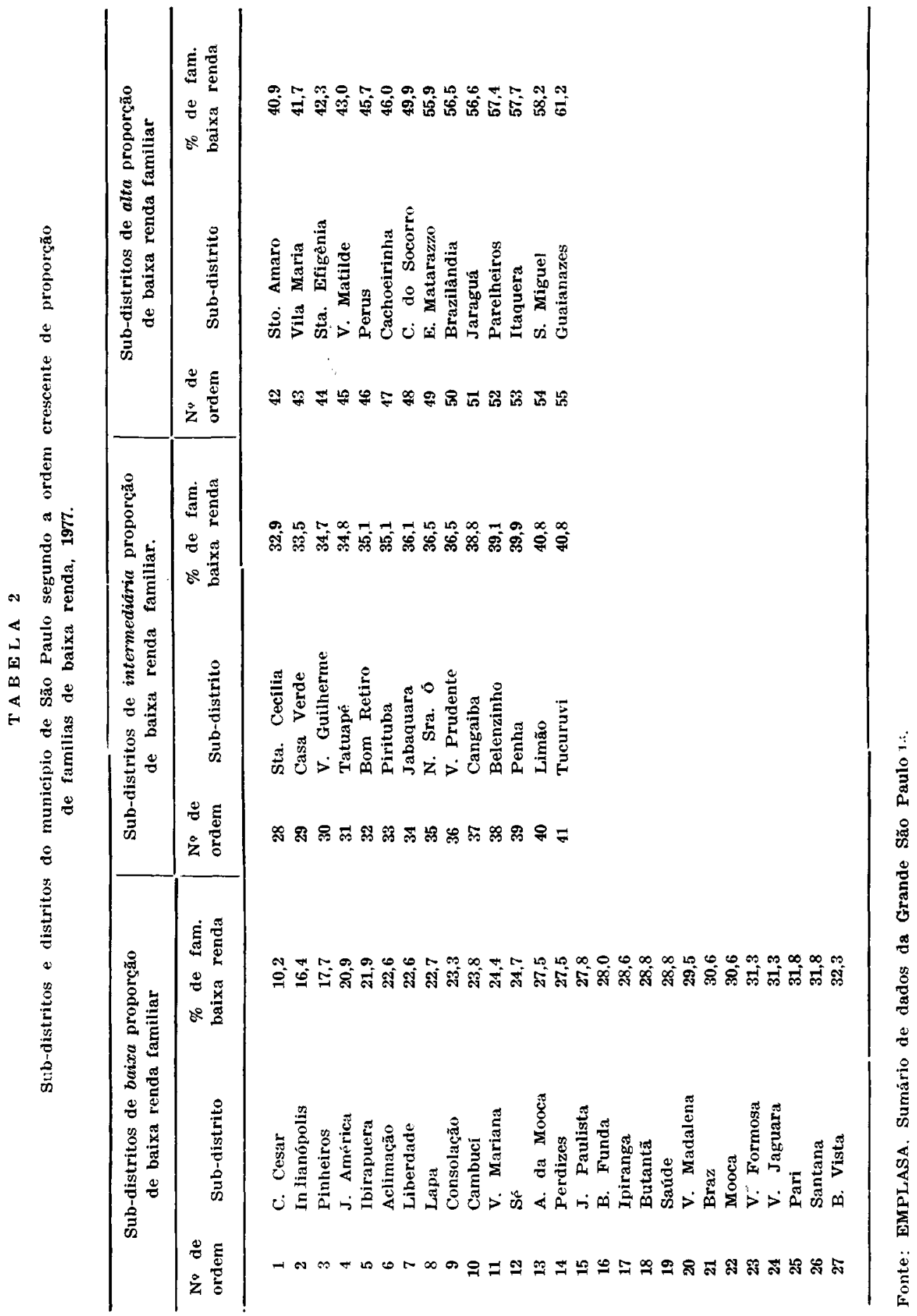




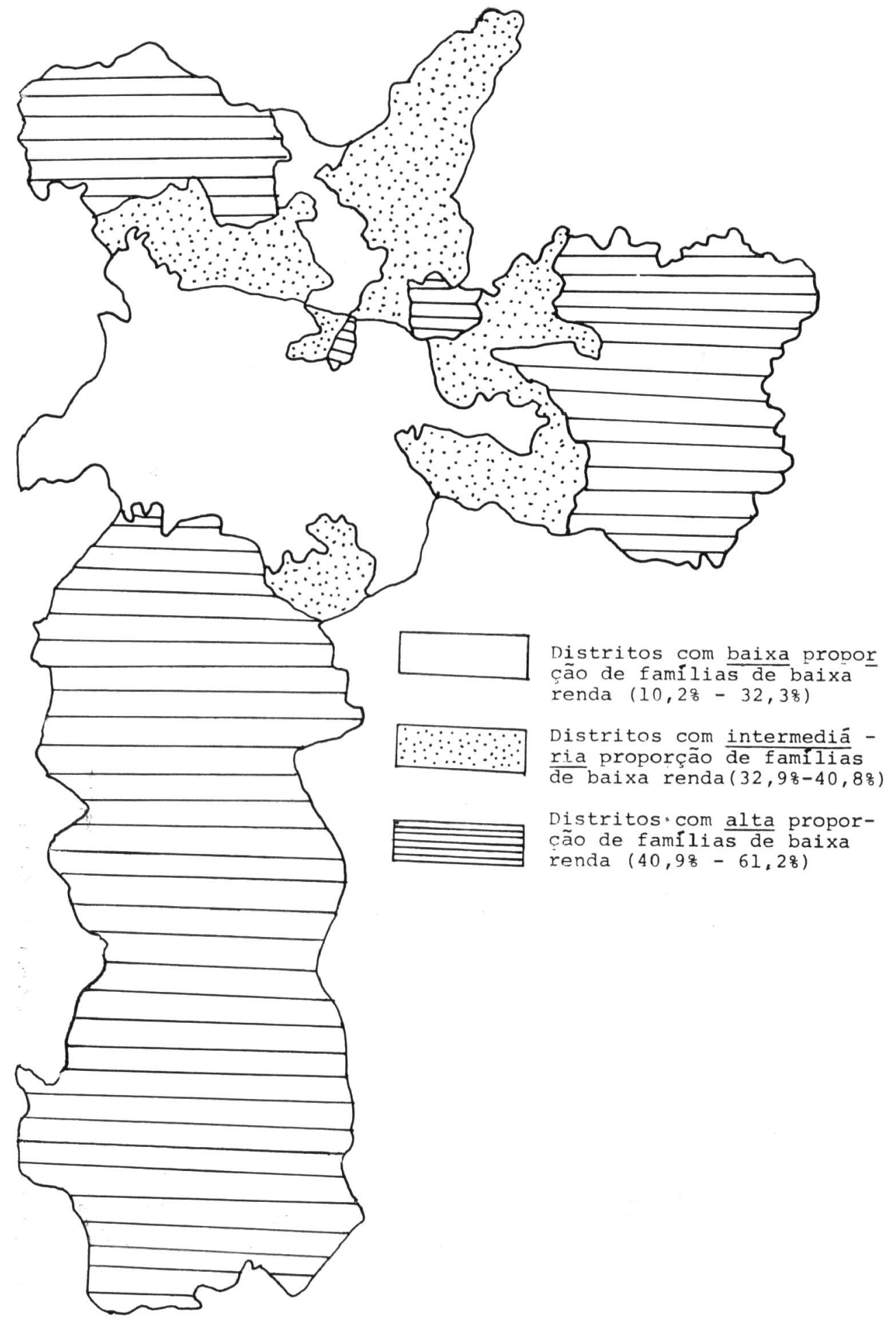

Fig. 3 - Delimitação das áreas de baixu, intermediária e altu proporção de familias de baixa renda (São Paulo, 1977). 
MONTEIRO, C. A. et al. A mortalidade no primeiro ano de vida e a distribuiçăo de renda e de recursos públicos de saúde, São Paulo (Brasil). Rev. Saúde públ., S. Paulo, 14:515-39, 1980.

cador em cada sub-distrito e distrito deve refletir ao mesmo tempo proporção de domicilios ligados e consumo de água por ligação.

No 4" bimestre de $1976^{\circ}$ a SABESP registrou no município un consumo de água de 64.356.264 $\mathrm{m}^{\mathrm{s}}$, o que, considerando a população estimada para 1976, equivaleria a um consumo médio de $8,39 \mathrm{~m}^{3}$ de água por habitante, por bimestre.

A Tabela 3 traz ordenada de forma decrescente o consumo per capita de água registrado pela SABESP em cada um dos 55 sub-distritos e distritos de São Paulo. Este consumo variou de $97,42 \mathrm{~m}^{3} / \mathrm{hab} . / \mathrm{bi}$ mestre no central sub-distrito da Sé, onde todos os prédios estavan ligados à rede pública de água e onde havia un elevado consumo por ligação, a consumo zero nus periféricos distritos de Perus e Parelheiros, que até àquela data não contavam com nenhum domicilio abastecido pela SABESP.

Analogamente a divisão do nunicipio em très conjuntos de sub-distritos e distritos de diferentes intensidades de mortalidade, procede-se à divisão do mesmo em três conjuntos de diferentes consumos de água do abastecimento público. Os primeiros 27 sub-distritos com maiores consumos, de 11,72 a $97,42 \mathrm{~m}^{3} / \mathrm{hab} . /$ bimestre, constituem o conjunto de alto consumo per capita. Os seguintes 14 sub-distritos com consumos intermediários, de 4,97 a $10,64 \mathrm{~m}^{3} / \mathrm{hab} . / \mathrm{bi}-$ mestre, constituem o conjunto de intermediário consumo per capita. Os últimos 14 sub-distritos e distritos com menores consumos, de zero a $4,93 \mathrm{~m}^{3} / \mathrm{hab} . /$ bimestre, constituem a conjunto de baixo consumo per capita.

A Fig. 4 situa a posição dos três con. juntos formados à base do consumo per capita da água do abastecimento público. Ainda uma vez, configuram-se três agrupamentos concêntricos, o mais central correspondendo ao conjunto de sub-distritos de alto consumo e o mais periférico ao conjunto de baixo consumo.

\subsubsection{Distribuição dos leitos de maternidade}

Apesar de a maioria dos leitos de maternidade do municipio não pertencerem a hospitais governamentais, mas sim a hospitais com fins lucrativos ou de interesse filantrópico, são organismos do Estado os principais financiadores do parto hospitalar. Isto se dá através do repasse de recursos financeiros de instituições públicas como a Previdência Social, o Governo do Estado e a Prefeitura para as entidades privadas que atendem os partos. Por este motivo, neste estudo serão considerados todos os leitos-maternidade do municipio, independentenente de sua origem.

Segundo levantamento da Coordenadoria de Assistência Hospitalar da Secretaria da Saúde do Estado de São Paulo, em 1975 o município de São Paulo contava com 80 hospitais-maternidade que no seu conjunto ofereciam 3.584 Jeitos-maternidade. Considerando a população estimuada para o mesmo ano, haveria uma disponibilidade de 0,46 leitos-maternidade para cada mil habitantes, teoricamente suficiente para atender adequadamente todos os nascimento do municipio.

A Tabela 4 traz ordenada de forma decrescente a disponibilidade de leitos hospitalares para maternidade nos sub-distritos do município de São Paulo. Pode-se notar que 20 sub-distritos não possuem hospitalmaternidade e que nos 35 restantes a disponibilidade varia grandemente, de excessivos 7,75 leitos por mil habitantes a insuficientes 0,09 leitos por mil habitantes.

Também aqui procede-se a divisão do município em três áreas: a de alta, a de intermediária e a de baixa disponibilidade de leitos-maternidade. No entanto, a existência de 20 sub-distritos e distritos em igual situação, todos com disponibilidade zero de leitos, determinou que as três áreas fossem compostas não mais pelos sucessivos 27,14 e 14 sub-distritos da ordem decrescente de disponibilidade, mas pelos sucessivos 27,8 e 20 sub-distritos. 


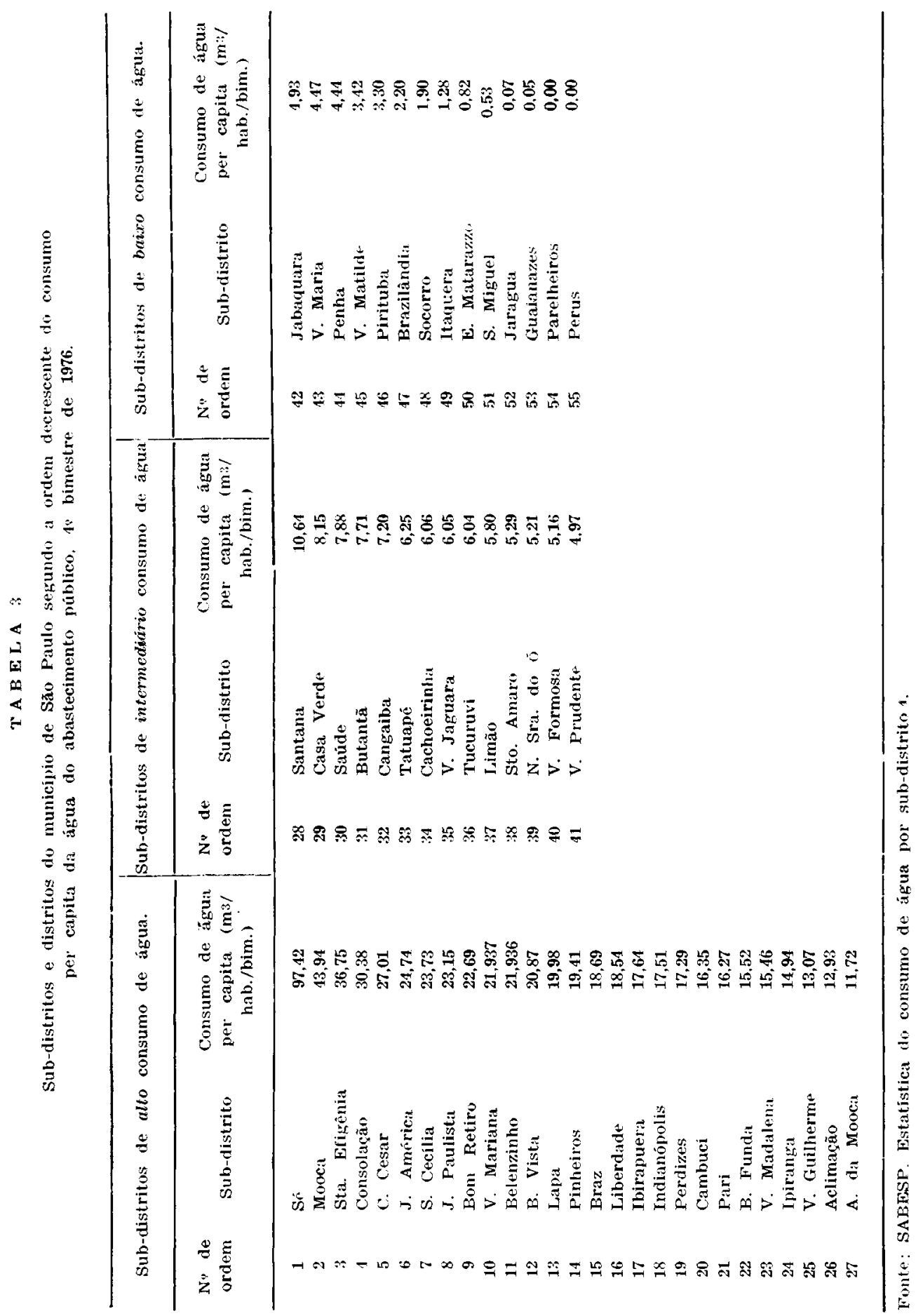




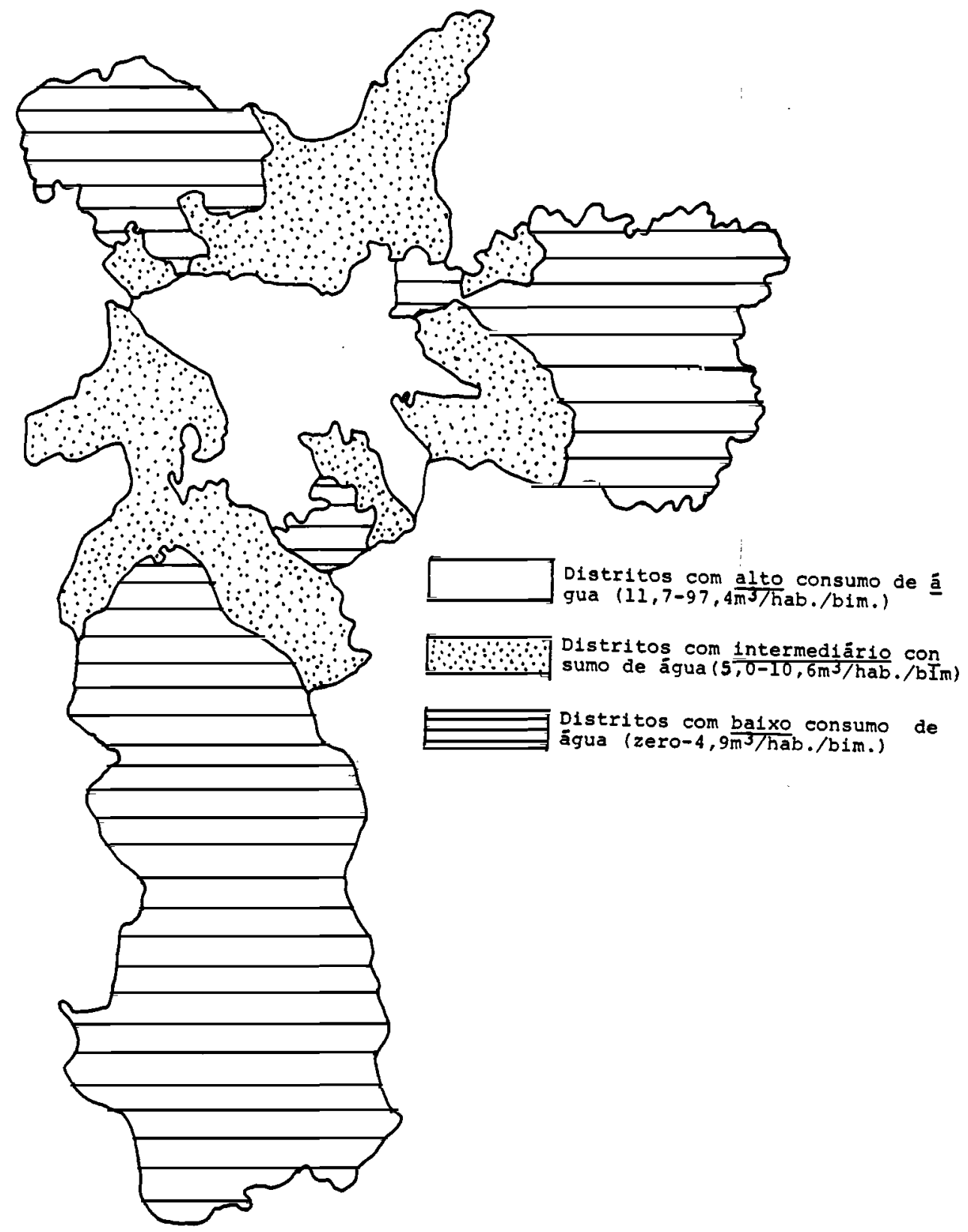

Fig. 4 - Delimitução das áreas de alto, intermediário e baixo consumo per capita de água da rede pública da SABESP (São Paulo, 1976). 


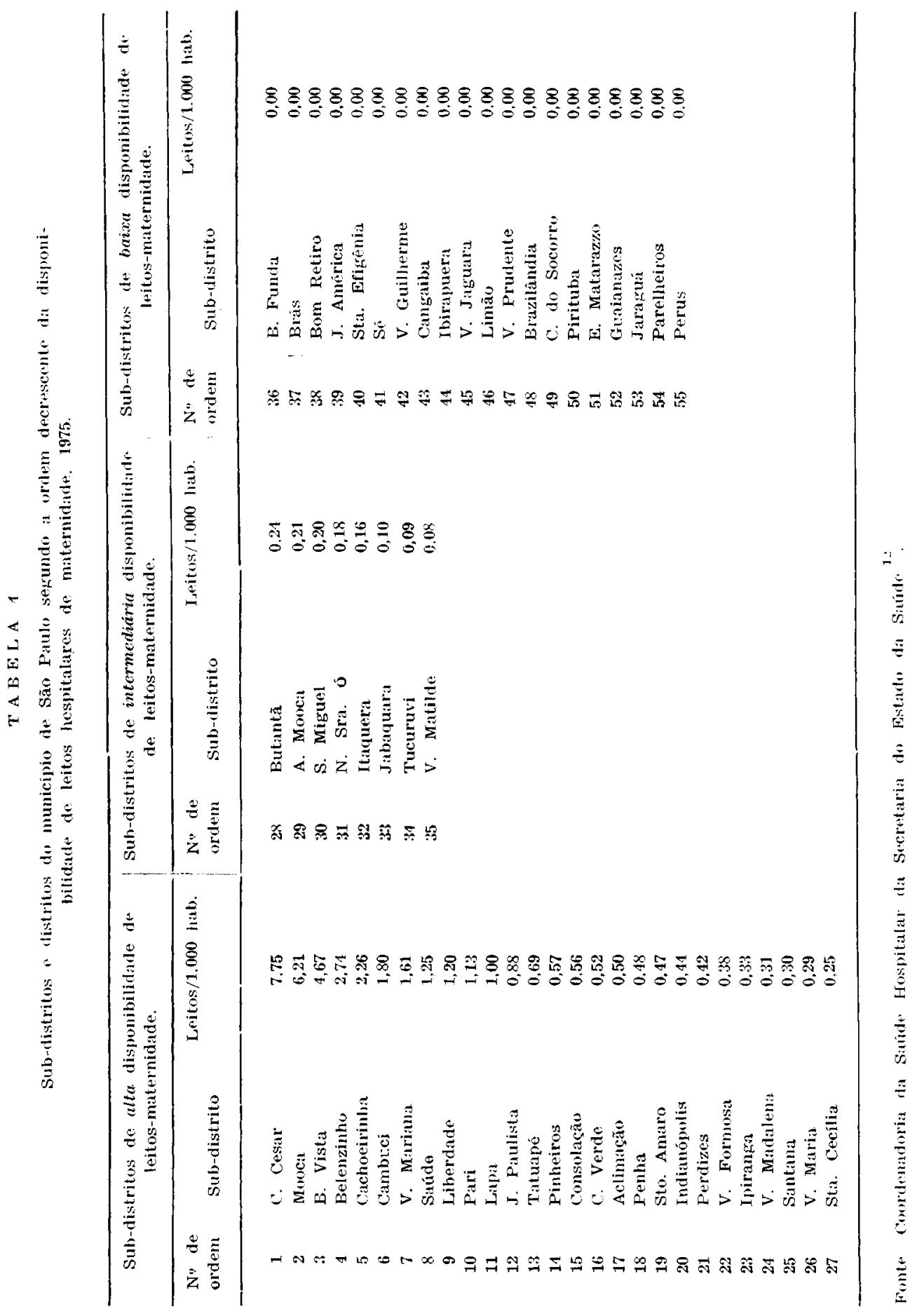


MONTEIRO, C. A. et al. A mortalidade no primejro ano de vida e a distribuição de renda e de recursos públicos de saúde, São Paulo (Brasil). Rev. Saúde pübl., S. Paulo, 14:515-39. 1980.

Assim, a área de alta disponibilidade de leitos-maternidade é constituida por subdistritos com 0,25 a 7,75 leitos por mil habitantes; a área de intermediária disponibilidade é constituída por sub-distritos com 0,08 a 0,24 ; e a área de baixa disponibilidade, na realidade, é constituida por sub-distritos sem leitos hospitalares para maternidade.

A Fig. 5 situa a posição dos três conjuntos formados a partir da disponibilidade de leitos-maternidade.

Diferentemente das distribuições anteriores, não há delimitaçōes nítidas entre os conjuntos formados. Pode-se notar, entretanto, que o conjunto de sub-distritos de alta disponibilidade de leitos-maternidade tende a se situar em áreas mais centrais da cidade enquanto que nas áreas mais periféricas tendem a se localizar os sub-distritos com intermediária ou nenhuma disponihilidade.

\subsubsection{Distribuição dos profissionais médicos dos centros de saude do Estado}

Em 1974, segundo o Departamento Técnico Normativo da Secretaria de Saúde do Estado, ò município de São Paulo contava com 400 profissionais médicos trabalhando em 133 centros de saúde do Estado (CSE). A população do município àquela época pode ser estimada em 7,059.400 habitantes 1) que indicaria uma disponibilidade média para o municipio de 0,57 profissionais médicos de CSE para cada 10.000 individuos. Esta disponibilidade, entretanto, também, não está homogeneamente distribuida, variando de 8,26 médicos $/ 10.000$ habitantes a 0,04 médicos $/ 10.000$ habitantes, havendo ainda 10 sub-distritos desprovidos de centros de saude do Estado (Tabela 5).

Analogamente a divisão do município em três áreas de diferentes intensidades de mortalidade, procede-se a divisão do município em três conjuntos de sub-distritos e distritos de diferentes disponibilidades de profissionais médicos de CSE. Os primeiros 27 sub-distritos de mainres disponibilidades,
0,39 a 8,26 médicos de CSE/10.000 habitantes, constituen o conjunto de alta disponibilidade de médicos de CSE. Os seguintes 14 sub-distritos de intermediárias disponibilidades, de 0,12 a 0,37 constituem o conjunto de intermediária disponibilidade de médicos de CSE. Os últimos 14 sub-distritos de menores disponibilidades, de 0,00 a 0,11 , constituem o conjunto de baixa disponibilidade de médicos de CSE.

A Fig. 6 situa a posição dos três conjuntos formados a partir da disponibilidade de médicos dos CSE, entretanto o entremeamento espacial dos conjuntos definitivamente impede a delimitação geográfica dos mesmos.

\subsection{Distribuição da renda e distribuição da mortalidade infantil}

A análise estatistica das Tabelas 1 e 2, onde os $\mathbf{5 5}$ sub-distritos do município aparecem ordenados de forma crescente segundo a frequiência proporcional de óbitos infantis e depois segundo a freqüencia proporcional de familias de baixa renda, revela que a forma crescente pela qual se distribui a proporção de óbitos infantis está positivamente correlacionada à forma crescente pela qual se distribui a baixa renda, sendo o grau de correlação de postos de Spearman igual a 0,74 (Tabela 6 ).

Torna-se evidente na Tabela 7 a superposição aparente dos três agrupamentos formados de acordo com a intensidade da freçiência proporcional da mortalidade infantil com os três agrupamentos formados de acordo com a intensidade da frequência proporcional da baixa renda, sugerida pela comparação das Figs. 2 e 3 . Pode-se verificar yue 41 dos 55 sub-distritos do município, ou seja, 74,54\% classificam-se de forma idêntica quanto à freqüência proporcional de óbitos infantis e de baixa renda. Verifica-se, também, que nos extremos das classificaçóes os agrupamentos de menores concentrações de óbitos infantis e de pobreza compartilham $81,48 \%$ de seus subdistritos (22 em 27) e os de maiores concentraçĩes $78,57 \%$ (11 em 14). 
MONTEIRo, C. A. et al. A mortalidade no primeiro ano de vida e a distribuiçăo de renda e de recursos públicos de saúde, São Paulo (B rasil). Rev. Saúde publ., S. Paulo, 14:515-39, 1980.

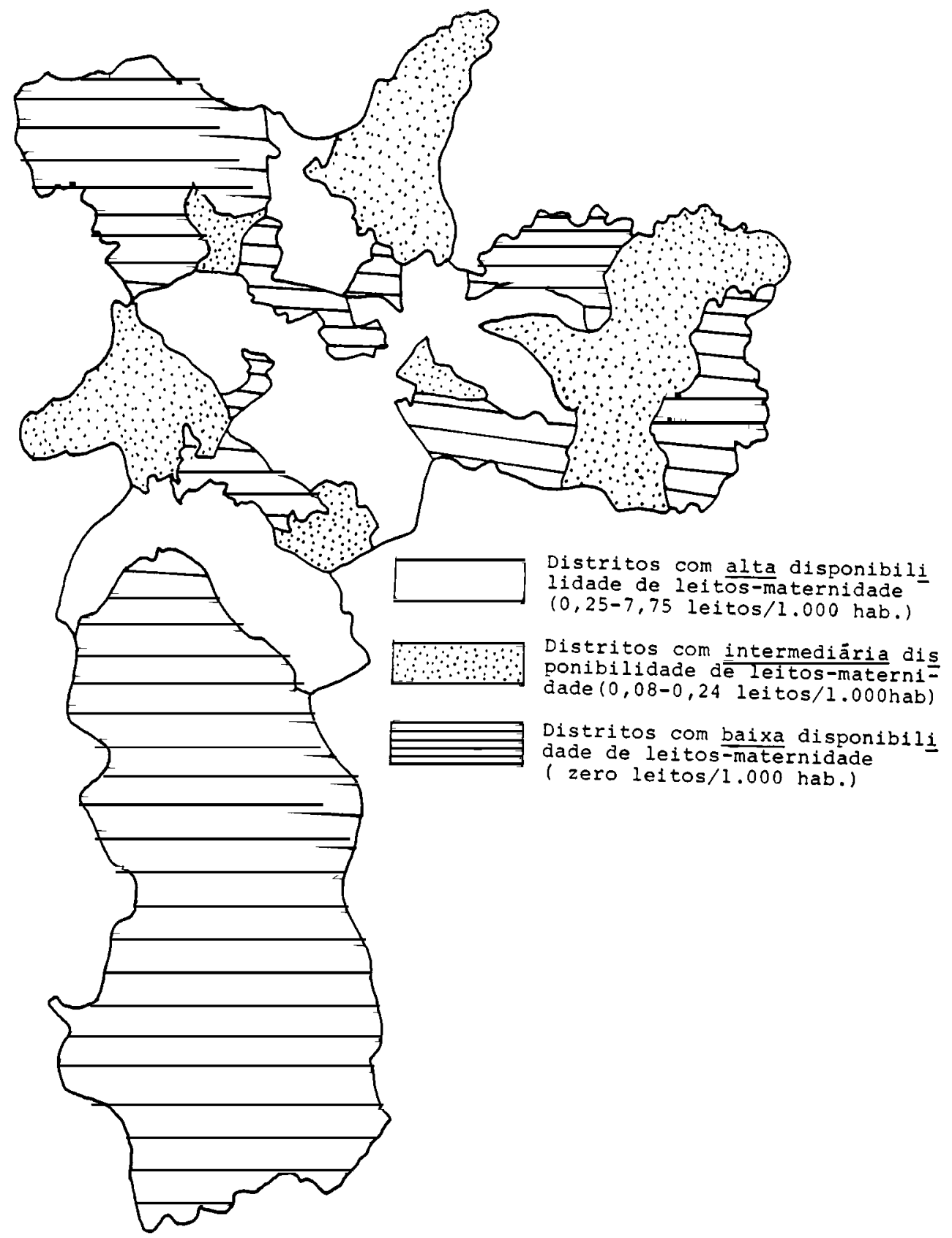

Fig. 5 - Delimitaçåo das áreas de alta, intermediária e baixa disponibillada de leitos maternidade (São Paulo, 1975). 


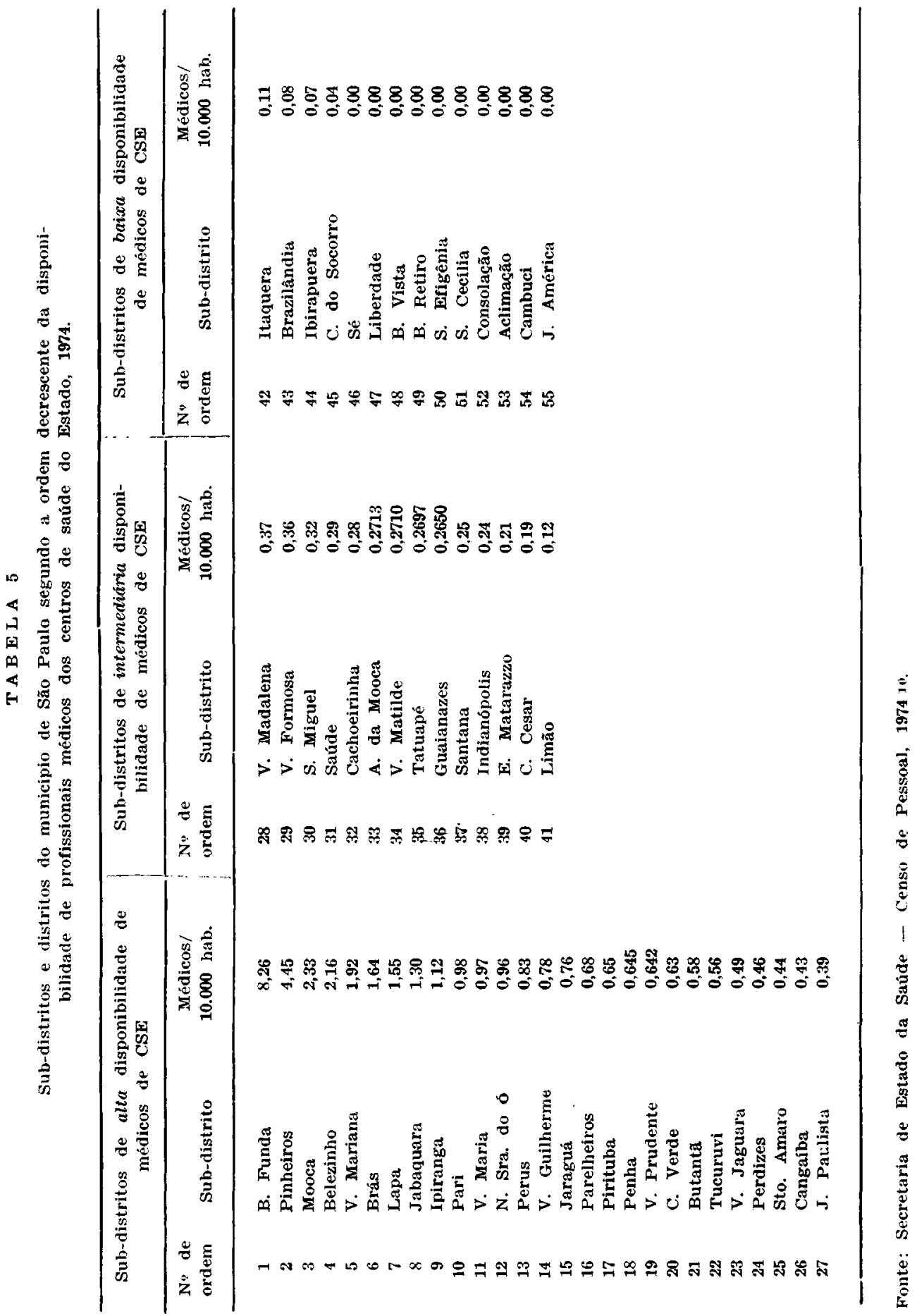


MONTEIRo, C. A. et al. A mortalidade no primeiro ano de vida e a distribuição de renda e de recursos públicos de saúde, São Paulo (Brasil), Rev. Saúde públ., S. Paulo, 14:515-39, 1980.

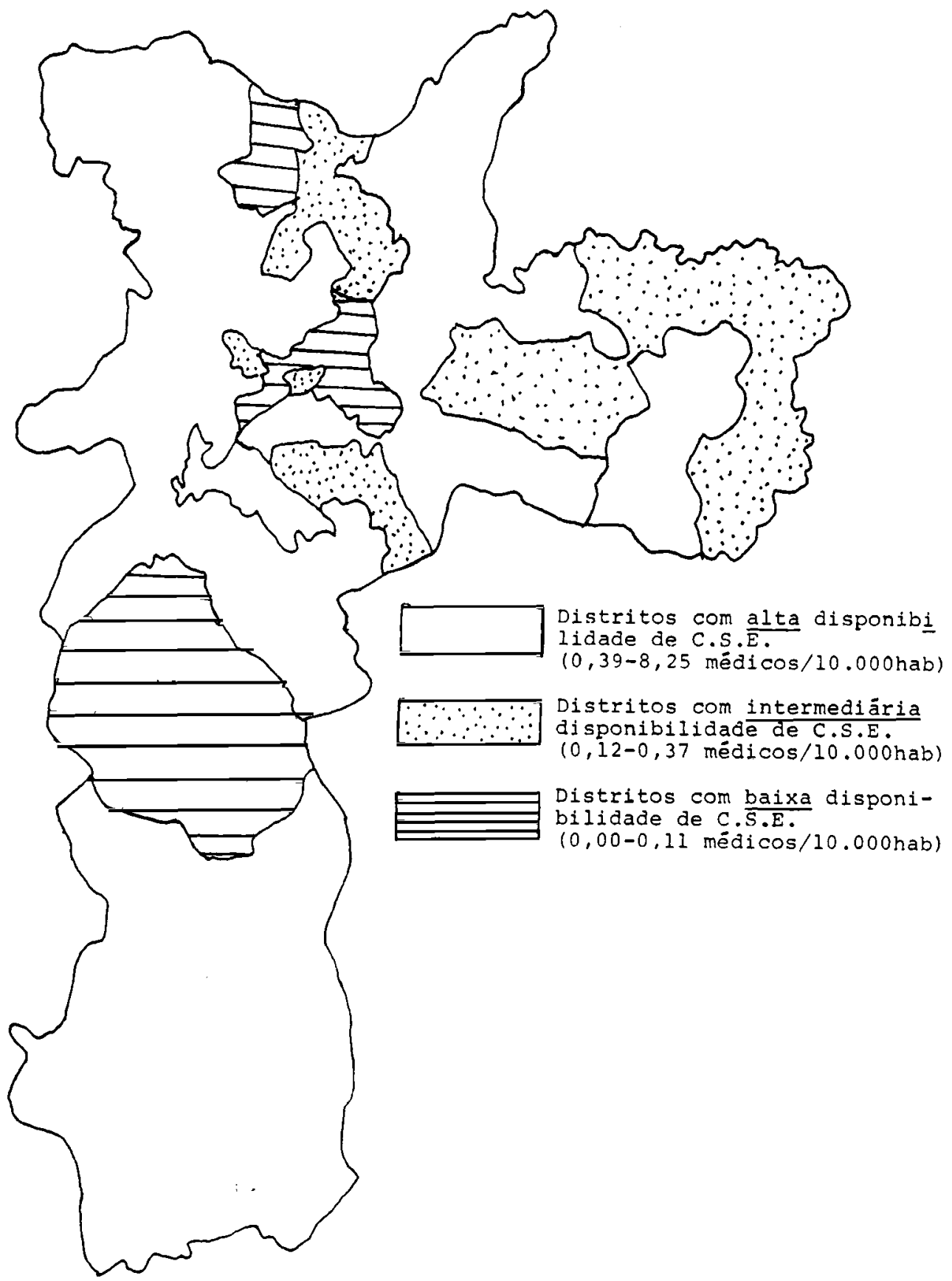

Fig. 6 - Delimitação de areas de alta, intermediaria e baixa disponibilidade de Centros de Saúde do Estado (São Paulo, 1974). 
MONTEIRo, C. A. et al. A mortalidade no primeiro ano de vida e a distribuição de renda e de recursos públicos de saúde, São Paulo (Brasil), Rev. Saúde públ., S. Paulo, 14:515-39, 1980.

\section{T A B E L A 6}

Coeficiente de currelação de pustos de Spearman entre pustos na mortalidade infantil proporcional e postos na baixa renda familiar e na disponibilidade ou consumo de determinados recursos públicos de saúde (Sub-distritos e distritos de São Paulo, 1974-1977).

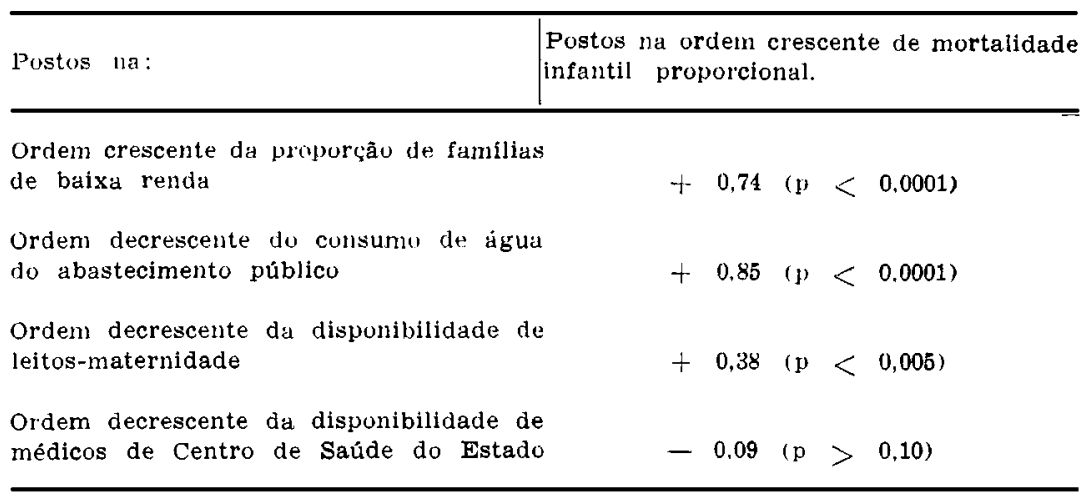

T A B E L A 7

Sub-distritos e distritos do município de São Paulo classificados segundo a frequencia proporcional de óbitos infantis e a frequiencia proporcional de familias de baixa renda, 1976-1977.

\begin{tabular}{l|ccc|c}
\hline $\begin{array}{l}\text { Proporção de } \\
\text { óbitos infantis }\end{array}$ & $\begin{array}{c}\text { Proporção de famílias de baixa renda } \\
\text { Baixa }\end{array}$ & Intermediária & Alta \\
\hline Baixa & 22 & 4 & 1 & Total \\
Intermediáría & 4 & 8 & 2 & 14 \\
Alta & 1 & 2 & 11 & 14 \\
\hline Total & 27 & 14 & 14 \\
\hline
\end{tabular}

O estudo da distribuição de renda internamente a cada uma das populaçōes das três áreas de diferentes intensidades da freqüência proporcional da mortalidade. infantil aponta, em média, $23,2 \%$ de famílias de baixa renda na área de baixa mortalidade, $35,9 \%$ na área intermediária mortalidade e $48,2 \%$ na área de alta mortalidade (Tabela 8).

\subsection{A distribuiçào dos recursos páblicos e a distribuição da mortalidade intantil}

\subsubsection{Abastecimento de água e mortalidade infantil}

A análise estatística das Tabelas 1 e 3 . onde os 55 sub-distritos e distritos do mu- 
MONTEIRo, C. A. et al. A mortalidade no primeiro ano de vida e a distribuição de renda e de recursos públicos de saúde, São Paulo (Brasil). Rev. Saúde públ., S. Paulo, 14:515-39, 1980.

TA BELA 8

Percentagem de famílias de baixa renda e disponibilidade ou consumo de determinados recursos públicos de saúde em trés áreas do municipio de são Paulo.

\begin{tabular}{l|c|c|c|c}
\hline $\begin{array}{c}\text { Area do } \\
\text { município (1) }\end{array}$ & $\begin{array}{c}\text { \% de famílias de } \\
\text { baixa renda (2) }\end{array}$ & $\begin{array}{c}\text { m3 de água tratada } \\
\text { da SABES por } \\
\text { hab./bim. (3) }\end{array}$ & $\begin{array}{c}\text { Leitos-materni- } \\
\text { dade/1.000hab. } \\
(4)\end{array}$ & $\begin{array}{c}\text { Médicos de } \\
\text { CSE/10.000 } \\
\text { hab. (5) }\end{array}$ \\
\hline $\begin{array}{l}\text { Baixa mortalidade } \\
\text { infantil proporcional }\end{array}$ & 23,2 & 0,98 & 0.82 \\
$\begin{array}{l}\text { Intermediária mor- } \\
\text { talidade infantil pro- } \\
\text { porcional }\end{array}$ \\
$\begin{array}{l}\text { Alta mortalidade in- } \\
\text { fantil proporcional }\end{array}$
\end{tabular}

(1) Conforme TABELA 1

(2) $\operatorname{Em} 1977$

(3) $\operatorname{Em} 1976$

(4) Em 1975

(5) $\operatorname{Em~} 1974$

nicípio aparecen ordenados primeiro de forma crescente segundo a frequêencia proporcional de óbitos infantis e depois de forma decrescente segundo o consumo de água do abastecimento público, revela que a forma crescente pela qual se distribui a proporção de óbitos infantis está positivamente correlacionada à forma decrescente pela qual se distribui o consumo per capita de água, sendo o grau de correlação medido por $r_{s}$ igual a 0,85 (Tabela 6).

$\mathrm{Na}$ Tabela 9 torna-se evidente a superposição aparente dos três agrupamentos formados de acordo com a intensidade da freqüência proporcional de óbitos infantis com os três agrupamentos formados de acordo com o volume de água consumido pelos habitantes, sugerida pela comparação das Figs. 2 e $4 . \quad$ Verifica-se que os agrupamentos de baixa mortalidade e alto consumo compartilham $96,30 \%$ de sets subdistritos (26 em 27), os de intermediária mortalidade e intermediário consumo compartilham $71,43 \%$ (10 em 14), e os de alta mortalidade e baixo consumo compartilham $78,57 \%$ (11 em 14).
O estudo da distribuiçào do consumo de água internamente a cada uma das três áreas de diferentes intensidades da freqüência proporcional da mortalidade infantil aponta em média um consumo bimestra! per capita de $18,21 \mathrm{~m}^{3}$ na área de baixa mortalidade, $6,46 \mathrm{~m}^{3}$ na área intermediária e $3,14 \mathrm{~m}^{3}$ na área de alta mortalidade ( $\mathrm{Ta}$. bela 8 ).

\subsubsection{Leitos-maternidade e mortalidade infantil}

A análise estatistica das Tabelas 1 e 4 , onde os 55 sub-distritos e distritos do município aparecem ordenados primeiro de torma crescente segundo a frequiência proporcional de óbitos infantis e depois de forma decrescente segundo a disponibilidade de leitos-maternidade, revela que a forma crescente pela qual se distribui a proporção de óbitos infantis acha-se positivamente correlacionada à forma decrescente pela qual se distribui a disponibilidade de leitosmaternidade, sendo o grau de correlação de postos de Spearman de 0,38 (Tabela 6). 
MONTEIRO, C. A. et al. A mortalidade no primeiro ano de vida e a distribuiq̧ăo de renda e de recursos públicos de saúde, São Paulo (Brasil). Rev. Saúde públ., S. Paulo, I4:515-39, 1980.

T A B E L A 9

Sub-distritos e distritos do municipio de São Paulo classificados segundo a frequéncia proporcional da mortalidade infantil e o consumo per capita da água do abastecimento público, 1976.

\begin{tabular}{|c|c|c|c|c|}
\hline $\begin{array}{l}\text { Proporção de } \\
\text { óbitos infantis }\end{array}$ & $\begin{array}{l}\text { Cor } \\
\text { Alto }\end{array}$ & $\begin{array}{l}\text { per capita d } \\
\text { Intermediário }\end{array}$ & $\begin{array}{l}\text { água } \\
\text { Baixo }\end{array}$ & Total \\
\hline Baixa & 26 & 1 & - & 27 \\
\hline Intermediária & 1 & 10 & 3 & 14 \\
\hline Alta & 一 & 3 & 11 & 14 \\
\hline Total & 27 & 14 & 14 & 55 \\
\hline
\end{tabular}

O estudo da distribuiçâo da disponibilidade de leitos-maternidade internamente a cada uma das três áreas de diferentes intensidades da freqüência proporcional da mortalidade infantil, levando em conta o conjunto de leitos e de população de cada uma, aponta em média 0,98 leitos por mil habitantes na área de baixa mortalidade, 0,32 na área de intermediária mortaljdade e 0,20 na área de alta mortalidade (Tabela 8 ).

\subsubsection{Médicos de centro de saúde $e$ mortalidade infantil}

A análise estatistica das Tabelas 1 e 5 , onde os sub-distritos e distritos do municipio aparecem ordenados primeiro de forma crescente segundo a freqüência proporcional de óbitos infantis e depois de forma decrescente segundo a disponibilidade de médicos de CSE, revela correlação muito próxima a zero, de $-0,09$ (Tabela 6).

Entretanto, o estudo da distribuição da disponibilidade de profissionais médicos do CSE, internamente a cada uma das três áreas de diferentes intensidades da frequiência proporcional da mortalidade infantil, levando em conta o conjunto de médicos e de população de cada uma, aponta resultados na mesma linha dos anteriores. Há em média 0,82 médicos para cada 10.000 habitantes na área de baixa mortalidade, 0,49 na área de intermediária mortalidade e 0,43 na área de alta mortalidade (Tabela 8 ).

\section{DISCUSSAO}

Com 75,03 óbitos infantis para cada mil crianças nascidas vivas, a cidade de São Paulo ostenta em 1976 uma elevada mortalidade infantil. Elevada em relação a cidades altamente desenvolvidas como Göteborg na Suécia, onde aquele coeficiente é de 9 por mil ${ }^{6}$; também elevada em relação a complexas metrópoles como New York, 17 por mil 5 , e ainda elevada em relação a cidades latino-americanas como Havana 7 e Buenos Aires 2, 18 por mil e 30 por mil, respectivamente.

O estudo da distribuição espacial da freqüência dos óbitos infantis no município revela claramente não ser homogênea esta distribuição. Confirmando o que já havia 
MONTEIRO, C. A. et al. A mortalidade no primeiro ano de vida e a distribulção de renda e de recursos públicos de saúde, são Paulo (Brasil). Rev. Saúde públ., S. Paulo, 14:515-39, 1980.

sido apontado por Baldijão ${ }^{3}$, ainda que com outra metodologia para o ano de 1971, a mortalidade infantil nos sub-distritos e distritos periféricos da cidade chega a ser quase duas vezes maior do que a mortalidade observada nos sub-distritos centrais. Indicada pelo acompanhamento da proporção de óbitos infantis no conjunto dos óbitos, a mortalidade infantil dá mostra de sofrer um aceleramento espantosamente uniforme à medida em que se afasta do centro em direção à periferia da cidade.

Os resultados da distribuição de renda no município săo claros, confirmando 0 processo geral vigente de extrema concentração de riquezas. A distribuição geográfica das famílias de baixa renda, isto é, famílias com rendimentos incompativeis com a subsistência, revela também heterogeneidade. Do modo geral, o mesmo processo de aceleração visto no caso da proporção de óbitos infantis conforme se caminhe do centro para a periferia da cidade, está presente quando a variável em questão é a proporção de familias de baixa renda. A identidade das duas distribuições, visualizada na comparação dos mapas respectivos e quantificada no coeficiente de correlação de 0,74 , é responsável pelo fato de que as familias de baixa renda sejam duas vezes mais freqüentes na área de alta mortalidade do que na área de baixa mortalidade, $48,2 \%$ contra $23,2 \%$.

A distribuição verificada quanto aos recursos públicos de Saúde aqui considerados - abastecimento de água, hospitaismaternidade e centros de saúde - exige de início a apreciação individualizada de cada uma das distribuiçōes.

A distribuição do consumo per capita de água, indicadora da proporção de domicilios ligados à rede e do consumo existente por ligação, mostra-se bastante desigual na cidade, seguindo tendência inversa à distribuição da proporção de óbitos infantis, ou seja, desacelerando-se à medida que se caminhe do centro para a periferia da cidade. A semelhança da distribuição crescente da mortalidade com a distribuição decrescente de consumo per capita de água, visualizada na comparação dos respectivos mapas e quantificada no coeficiente de correlação de 0,84 , traduz-se no fato de que o volume de água do abastecimento público consumido na área de alta mortalidade é 6 vezes menor do que o volume consumido na área de baixa mortalidade, $3 \mathrm{~m}^{3}$ per capita contra $18 \mathrm{~m}^{3}$ per capita no mesmo bimestre.

Admitindo yue na área de alta mortalıdade cada ligação da SABESP corresponda a um domicílio e que cada domicilio corresponda a 5 pessoas, poder-se-ia dizer que apenas $26 \%$ dos domicílios daquela área estariam em 1976 ligados à rede pública. O mesmo cálculo aplicado às duas outras áreas revelaria $68 \%$ de domicilios ligados à rede na área de intermediária mortalidade e $88 \%$ na área de baixa mortalidade. Dada a presença importante de prédios com mais de um domicílio nesta última área, possivelmente ai a cobertura da rede esteja sendo sensivelmente subestimada, o mesmo não ocorrendo entretanto com as duas outras áreas, onde mais frequientemente cada ligação corresponde a um único domicílio.

Quanto aos hospitais-maternidade da cidade, nota-se de inicio que no conjunto eles apresentam um número razoável de leitos, uma vez que com 0,46 leitos por mil habitantes seria teoricamente possivel atender a todos os nascimentos do municipio com uma média de 5 dias por internação. Considerando, entretanto, a situaçāo de cada sub-distrito e distrito, a situação deixa de ser favorável para muitos deles.

Primeiramente, 20 dos sub-distritus e distritos do município não contavam em 1975 com nenhum hospital-maternidade. Entre estes havia sub-distritos pequenos e centrais como Sé, Barra Funda, Brás, Bom Retiro, Jardim América e Santa Efigênia, onde esta inconveniência é relativa dada a proximidade das maternidades situadas nos sub-distritos contígüos. Porém, havia também 
MONTEIRo, C. A. et al. A mortalidade no primeiro ano de vida e a distribuição de renda e de recursos públicos de saúde, São Paulo (Brasil). Rev. Saúde públ., S. Paulo, 14:515-39, 1980.

sub-distritos periféricos extensos e populosos como Vila Prudente, Capela do Socorro, Ermelino Matarazzo, Brazilândia, Pirituba e Guaianazes, cuja população em conjunto, em 1975, era superior a um milhão e trezentos mil habitantes e, ainda, distritos como Perus, Jaraguá e Parelheiros onde nem mesmo os sub-distritos limítrofes apresentavam hospitais-maternidade.

Além dos 20 sub-distritos e distritos sem maternidades, outros 16 não chegavam à média razoável de disponibilidade de leitos de 0,46 leitos-maternidade por 1.000 habitantes.

A distribuição espacial da disponibilidade de leitos-maternidade no município, dada a presença de sub-distritos centrais desprovidos de maternidade, não chega a mostrar uma tendência uniforme de redução de disponibilidade à medida que se caminha do centro para a periferia. Entretanto, notase que a correlação entre a ordem crescente da frequiência do óbito infantil e a ordem decrescente da disponibilidade de leitosmaternidade foi positiva e significativa, ainda que de magnitude inferior às anteriores. E, mais importante, considerando os leitos-maternidade e a população presente nas áreas de diferentes intensidades da mortalidade infantil proporcional, verifica-se que a disponibilidade daqueles leitos na área de alta mortalidade é 5 vezes inferior à disponibilidade na área de baixa mortalidade, 0,20 leitos $/ 1.000$ habitantes contra 0,98.

A adequação dos CSE à população do municipio é bastante complexa de ser apreciada, dada a multiplicidade de serviços e instituições responsáveis pela atenção primária à saúde na cidade. É a rede de CSE no entanto, aquela que teoricamente deveria atender a toda população carente do municipio; é ela também que conta com um alentado Programa de Assistência MaternoInfantil que inclui desde a distribuição de cloro para a desinfeç̧ão da água utilizada pelos domicílios não ligados à rede pública até a suplementação alimentar para preenchimento das deficiências alimentares de gestantes e crianças; ainda é a rede de CSE a estrutura que declaradamente recebe do Estado a função de "combater" os elevados niveis de mortalidade infantil. É com este sentido que se faz o exame da distribuição deste recurso público de saúde. estudado aqui, através do médico que é o fulcro de toda a programação daqueles CSE.

De inicio, detecta-se que 10 sub-distritos do município em 1974 não possuiam nenhum CSE. Entretanto, diferentemente do que ocorre no caso das maternidades, estes sub-distritos na sua totalidade são pequenos e localizados no centro da cidade com alternativas relativamente próximas de CSE nos sub-distritos contigüos. Este fato $e$ o encontro de alta disponibilidade em alguns poucos populosos porém extensos distritos periféricos como Parelheiros, Perus e Jaraguá impedem que se caracterize uma tendência uniforme de decréscimo da disponibilidade de médicos à medida que se avance do centro para a periferia da cidade, e implicam na ausência de correlação entre a ordem crescente da proporção de óbitos infantis e a ordem decrescente da disponibilidade de médicos de CSE. Entretanto, aqui também, a consideração dos médicos e da população existentes em cada uma das três áreas de diferente mortalidade infantil proporcional revela resultados igualmente desvantajosos para a área de alta mortalidade, que detinha em média duas vezes menos médicos por população do que a área de baixa mortalidade, 0,43 médicos/ 10.000 habitantes contra 0,82 .

Sintetizando a distribuição dos recursos públicos de Saúde pode-se concluir, portanto, que: recursos públicos como os CSE, criados e operados pelo Estado para atender dirigidamente a população mais carente; recursos públicos como as maternidades, de modo geral não operadas pelo Estado diretamente, mas contando com seu decisivo apoio financeiro via convênios; e, finalmente, recursos públicos como a rede de abastecimento de água, sustentada em parte pelos usuários, porém fortemente subsidiada pelo 
MONTEIRo, C. A. et al. A mortalidade no primeiro ano de vida e a distribuição de renda e de recursos públicos de saúde, São Paulo (Brasil). Rev. Saúde públ., S. Paulo, 14:515-39, 1980.

Estado, acham-se todos tão desigualmente distribuidos na cidade quanto a renda. Ambos, renda e recursos públicos estão distribuidos na mesma direção, ou seja, de reforço mútuo às desigualdades registradas ao nivel da distribuição da mortalidade infantil, considerada esta um excelente indicador da qualidade de vida desfrutada pela população.
Vê-se, portanto, que a população mais desfavorecida da cidade, que vive em sua periferia sofre as conseqüências de duas distribuiçōes injustas: em um primeiro momento, na divisão das riquezas produzidas; em um segundo momento, quando parte dessas riquezas, depois de amealhadas pelo Estado através de impostos, são redistribuidas na forma de serviços.

RSPUB9/528

MONTEIRO, C. A. et al. [Mortality within the first year of life in relationship to the distribution of income and of public facilities, S. Pallo (Brasil)] Rev. Saúde públ., S. Paulo, 14:515-39, 1980.

ABSTRACT: It was made a study to identify the distribution of the infant death rates and the distribution of income, and the distribution of certain public health facilities in the 55 districts of the city of S. Paulo (Brazil) and, then, to analyze the similarity among them. The infant death rates and concentration of low income families increased from the center to the periphery of the city. The public health facilities - water supply, maternity beds, and State health centers - also decreased from the center to the periphery of the city. Both the increasing distribution of income and the decreasing distribution of public facilities were positively related to the increasing mortality distribution. The conclusion, therefore, is that, in S. Paulo, income and public facilities are synergic; that is, they mutually reinforce the inequalities observed through the infant mortality.

UNITERMS: Infant mortality, S. Paulo, Brazil. Income. Health facilities.

\section{REFERENCIAS BIBLIOGRAFICAS}

1. ANTONOVSKI, A. \& BERNSTEIN, J. Social class and infant mortality Soc. Sci. Med., $11: 453-70,1977$.

2. ARRUNADA, M. et al. Diferenciales socio. economicos de la mortalidad infantil. Capital Federal, Argentina, 1976 (inédito). apud BEHM, H. Socioeconomic. determinants of mortality in Latin America. Geneva, World Heaith Organization. 1979. (DSI/Se/WP/79.6).

3. BALDIJAO, M. F. A. Infant mortality, malnutrition, and infectious diseases in São Paulo, Brazil. Ithaca. 1979. [Dissertação de Mestrado - Cornell Un1versity]
4. COMPANHIA DE SANEAMENTO BASICO DO ESTADO DE SAO PAULO. Estatistica de consumo de agua por subdistrito: $4^{\circ}$ bimestre/76. São Paulo, 1976.

5. DEPARTMENT OF HEALTH. Bureau of Heaith Statistics and Analysis. Summary of vital statistics 1978. New York, 1979.

6. FALKNER, F. Fundamentals of mortality risks during the perinatal period and infancy. Basel, 1977. (Monographs in Pediatrics, 9.9 ).

7. INFORME ANUAL DEL MINISTERIO DE SALUD PUBLICA: 1978. La Habana, Cuba, 1979. 
MONTEIRo, C. A. et al, A mortalidade no primeiro ano de vida e a distribuição de renda e de recursos públicos de saúde, São Paulo (Brasil). Rev. Saúde públ., S. Paulo, 14:515-39, 1980.

8. IUNES, M. et al. Estado nutricional de crianças de 6 a 60 meses no municipio de São Paulo. São Paulo, Departamento e Instituto de Medicina Preventiva da Escola Paulista de Medicina, 1975. [mimeografado]

9. LAURENTI, R. Alguns aspectos particulares referentes aos resultados da Investigação Interamericana de Mortalidade na Infáncia na área do projeto de São Paulo, Brasil, Bol. Ofic. sanit. panamer., 89:1-14, 1975.

10. LESER, W. S. P. et al. Região metropoil. tana de São Paulo: diagnóstico 75; Desenvolvimento S6cio-Econômico: Saüde. Sāo Paulo, 1975.
11. SECRETARIA DE ECONOMIA E PLANEJAMENTO. Movimento do registro civil do Estado de São Paulo: 1974 a 1976. São Paulo, 1977. (Estudos e Pesquisas, 12).

12. SECRETARIA DE ESTADO DA SAŨDE. Coordenadoria de Assistência Hospitalar. Levantamento de recursos hospitalares do Estato de São Paulo. São Paulo, 1976.

13. SUMARIO de da:Tos da Grande São Paulo. São Paulo, EMPLASA, 1978.

Recebido para publicą̧ão em 28/05/1980

Aprovado para puliticaçāo em 23/06/1980

\section{RESUMOS DE LIVROS / BOOK REVIEWS}

Internacional CONGREss ON Disaster, Medicine Mainz, 1977. Types and evenis of disasters, organization in various disaster situations; edited by $R$. Frey and P. Safar. Berlin, Springer-Verlag, 1980. 355 p., 94 Fig. (Disaster Medicine, I).

"As características da vida hodierna - os acidentes resultantes da imensa gama de processos tecnológicos, a variedade e o poder dos meios de construção ou destruição (tanto na paz como na guerra) que estão modificando o nosso ambiente criaram condições para as quais o tratamento médico em massa pode ser adequadamente chamado de medicina de desatres. Métodos de medicina moderna são aplicados em situações inesperadas nas quais o número de pacientes excede de muito os meios disponiveis para atendê-los. Isso resulta em esquemas especiais de ordem deontológica, técnica e médica". Estas palavras abrem o Congresso Internacional de Medicina de Desastres, realizado em Mainz (Alemanha Ocidental), no período de 30 de setembro a 3 de outubro de 1977 e ao qual compareceram 105 participantes, que apresentaram 91 trabalhos que são apresentados, de forma resumida, neste bem impresso volume de 355 páginas. Os trabalhos são agrupados em três diferentes seçōes, cada uma delas dedicada a um tema especial. Na primeira seção é feito o estudo do tipo e das condições de ocorrências de desastres típicos de trem e de aviäo, de consequiências de terremotos, de guerras civis, etc., procurando demonstrar os problemas que decorrem quando grande número de pessoas é subitamente at ngido por desastres naturais ou provocados dos quais decorrem gravissimos problemas para a vida e o bem-estar das vítimas. $\mathrm{Na}$ segunda seção descrevem-se os tipos de organização local, regional e nacional que devem existir para fazer frente a esse tipo de desastre. As facilidades médicas e/ou hospitalares que habitualmente existem nas comunidades não têm condições de equipamento, material e pessoal para fazer frente a tais emergências, pelo que um sistema de pronto-atendimento de desastres dessa natureza deve ser previamente planejado e preparado. A terceira seção é dedicada a exemplos típicos de grandes desatres em vários paises e à forma pela qual os mesmos foram atendidos a nível local e regional. Não obstante a extensão necessariamente breve dos vários trabalho, a leitura desse livro é obrigatória para todos os estudiosos de Saúde Pública, uma vez que aborda um grave problema para o qual a grande maioria das comunidades está pouco ou nada aparejhada para enfrentar.

D. P. Nogueira 